\title{
Reproductive Health of Rats with Benign Prostatic Hyperplasia Following Cosmos caudatus Ethanolic Extract Consumption
}

\author{
Dzulsuhaimi Daud*, Nur Faza Mohd Fekery, Nooraain Hashim \\ School of Biology, Faculty of Applied Sciences, Universiti Teknologi MARA, 40450 Shah Alam, Selangor, Malaysia.
}

\begin{tabular}{|c|c|}
\hline ARTICLE INFO & ABSTRACT \\
\hline $\begin{array}{l}\text { Article history: } \\
\text { Received on: } 20 / 02 / 2017 \\
\text { Accepted on: } 24 / 04 / 2017 \\
\text { Available online: } 30 / 06 / 2017\end{array}$ & $\begin{array}{l}\text { The purpose of this study was to determine the effect of Cosmos caudatus ethanolic extract on reproductive } \\
\text { health of rats with testosterone-induced benign prostatic hyperplasia (BPH) by measuring daily urinary output, } \\
\text { prostate volume, prostatic index and sperm parameters. BPH was induced by subcutaneous injection of } \\
\text { testosterone undecanoate ( } 3 \mathrm{mg} / \mathrm{kg} \text { bwt), daily for } 20 \text { days. Then, } 16 \text { Sprague Dawley rats with BPH were }\end{array}$ \\
\hline $\begin{array}{l}\text { Key words: } \\
\text { Cosmos caudatus, sperm } \\
\text { parameters, benign prostatic } \\
\text { hyperplasia (BPH), prostate } \\
\text { volume, prostatic index. }\end{array}$ & $\begin{array}{l}\text { b.wt. of } C \text {. caudatus ethanolic extract (CCEE) daily for } 20 \text { days, respectively. Meanwhile, a group of healthy } \\
\text { Sprague Dawley rats }(\mathrm{n}=8) \text { served as a control and received } 2 \mathrm{ml} / \mathrm{kg} \text { bwt of DW daily for } 20 \text { days. At the end of } \\
\text { the experimental period, urinary volume was recorded and all rats were euthanized by over-dose of diethyl ether. } \\
\text { The prostate was quickly removed, cleaned and subjected to prostate volume and prostatic index determination. } \\
\text { Epididymis also was collected for sperm parameters evaluation. The results showed that, CCEE increased the } \\
\text { daily urinary output in rats with BPH. CCEE also reduced the prostate volume and prostatic index of rats with } \\
\text { BPH. Meanwhile, sperm parameters were not affected by BPH and CCEE. These results suggest that CCEE } \\
\text { demonstrated anti-BPH via anti-inflammatory without compromising sperm quality. Hence, C. caudatus } \\
\text { represent a potential herb for the treatment of BPH. }\end{array}$ \\
\hline
\end{tabular}

\section{INTRODUCTION}

Benign prostatic hyperplasia (BPH) is a urological disorder caused by the abnormal proliferation of epithelial and stromal cells in the prostate gland in elderly man (Sarbishegi et al., 2016). BPH common symptoms include inability to delay urination, incomplete emptying of the bladder, frequent urination during the day and night, weak urine stream, incontinence and painful or bloody urination (Asare et al., 2015). Two synthetic medications used for the treatment of BPH are $\alpha$-blockers and $5 \alpha$-reductase inhibitors (McVary, 2007). Due to the side effects of synthetic medications, phytotherapy which is the use of medicinal plants to heal and restore balance, is becoming more accepted and frequently used to alleviate the symptoms of

\footnotetext{
* Corresponding Author

Dzulsuhaimi Daud, School of Biology, Faculty of Applied Sciences, Universiti Teknologi MARA, 40450 Shah Alam, Selangor, Malaysia. Email: dzuls990@ gmail.com
}

BPH (Schmidt et al., 2013). The current study was conducted to investigate the potential of Cosmos caudatus to alleviate the symptoms. C. Caudatus or locally known in Malaysia as 'ulam raja', has the potential to be used in treating $\mathrm{BPH}$ and other reproductive-related issue since it possess high anti-oxidant capacity. Mustafa and co-workers (2010) documented that Cosmos caudatus has been found to contain phenolics, flavonoids, flavones and flavanones. Recent pharmacological studies confirm that $C$. caudatus has antibacterial, antifungal, antiosteoporosis, antihypertensive and antidiabetic effects (Bunawan et al., 2014). Toxicological studies demonstrated that $C$. caudatus can cause hepatotoxicity at higher doses but safe to be consumed at lower dosages (Farah-Amna et al., 2013; Bunawan et al., 2014). As far as our literature could ascertain, much attention has not been given to the effect of this useful plant on BPH and other aspects of male reproduction. Therefore, the present study was designed to test the hypothesis that $C$. caudatus ethanolic extract could eliminate the symptoms of BPH without compromising sperm quality. 


\section{MATERIALS AND METHODS}

\section{Plant materials collection and extraction}

The leaves of Cosmos caudatus were bought from local market in Section 6, Shah Alam, Selangor and taxonomically identified at the Herbarium, Universiti Kebangsaan Malaysia. The voucher specimen (UKMB40335) was deposited in our research laboratory for the future reference. The leaves were washed under running tap water and dried at $50^{\circ} \mathrm{C}$ in hot air oven (Memmert, Germany) to remove moisture. These dried leaves then subjected to size reduction using electrical blender (Pensonic PB-3203L, Malaysia), soaked in $70 \%$ ethanol (Kollins Chemicals, USA) for 3 days and evaporated using the rotary evaporator (Buchi Rotavapor R-210, Germany). The Cosmos caudatus ethanolic extract (CCEE) obtained was stored in a container at $4^{\circ} \mathrm{C}$ and reconstituted with distilled water prior to experimental assessment.

\section{Animals}

A total of 24 male Sprague Dawley rats (10-12 weeks old, 200-250 g) were purchased from commercial breeders (Chenur Supplier Sdn Bhd). The rats were acclimatized to laboratory environment $\left(21-23^{\circ} \mathrm{C}\right)$ with a $12 \mathrm{~h}$ light-dark cycle for 7 days prior to experimentation (Animal Holding Room, Faculty of Applied Sciences, Universiti Teknologi MARA). During the experimental period, the animals were fed ad libitum with rodent pellet and water.

The entire animal manipulations were performed in accordance to the guidelines and authorised by the Research Ethics Universiti Teknolog Committee of The Faculty of Applied Sciences, Universiti Teknologi MARA.

\section{Testosterone-induced BPH and anti-BPH evaluation}

Out of 24, eight male Sprague Dawley rats were retained normal and another 16 were injected sub-cutaneously with 3 $\mathrm{mg} / \mathrm{kg}$ bwt of testosterone undecanoate (Andriol Testocaps, Catalent France Beinheim SA, France), daily for 20 days to induce benign prostatic hyperplasia $(\mathrm{BPH})$ as previously described by Sarbishegi and co-workers (2016). Rats with BPH then were randomly divided into two experimental groups. The first eight rats with $\mathrm{BPH}(\mathrm{n}=8)$ were treated with $2 \mathrm{ml} / \mathrm{kg}$ bwt of distilled water (DW), daily for 20 days and another eight rats with $\mathrm{BPH}$ $(\mathrm{n}=8)$ were treated with $250 \mathrm{mg} / \mathrm{kg}$ bwt of Cosmos caudatus ethanolic extract (CCEE), daily for 20 days. Meanwhile, another eight normal and healthy rats $(\mathrm{n}=8)$ were treated with $2 \mathrm{ml} / \mathrm{kg}$ bwt of DW, also daily for 20 days.

At the end of the experimental period, the urine was collected from each rat using metabolic cage. Each rat was placed in individual metabolic cage and the urine was collected for the duration of 24 hours. Then the animal was sacrificed by over-dose of diethyl ether (Kollins Chemicals, USA) and the prostate was harvested for prostate volume and prostatic index determination (Afriyie et al., 2014). The prostate volume was determined by placing a prostate in measuring cylinder containing saline and calculating the volume change. The prostatic index was calculated by dividing prostate weight (g) with bodyweight (g) and multiplying by 100 .

\section{Sperm collection and sperm parameters evaluation}

Immediately after euthanasia, epididymis was collected, cleaned and placed into a $1 \mathrm{ml}$ phosphate buffer saline. Then, epididymis was minced using a small scissors and incubated for 30 minutes in $\mathrm{CO}_{2}$ incubator $\left(37^{\circ} \mathrm{C}, 5 \% \mathrm{CO}_{2}\right)$ to allow sperm to undergo swim up procedure. After that, Makler Counting Chamber (Sefi-Medical Instruments Ltd, USA) warmed to $37^{\circ} \mathrm{C}$ was loaded with a small aliquot $(5 \mu \mathrm{l})$ of sperm suspension. Sperm count was conducted under light microscope (Olympus CX21, Japan) using Makler Counting Chamber according to manufacturer's manual (Sefi-Medical Instruments Ltd, USA). Meanwhile, sperm motility evaluation was performed by the same person throughout the study and was assessed by visual estimation under the light microscope with x20 objective lense (Olympus CX21, Japan). For each sample, 100 sperm were observed in duplicate and classified as immotile and motile (without and with progressive movement) as previously described by Fernandez et al., (2011). For sperm morphology, the number and percentage of normal sperm was determined by examining air dried slide after staining with giemsa (Casarett, 1953).

\section{Statistical analysis}

The data presented as mean \pm standard error of mean (SEM) and were analysed by ANOVA. In all cases, $\mathrm{p}<0.05$ was considered statistically significant.

\section{RESULTS AND DISCUSSION}

A daily urinary output was decreased significantly $(\mathrm{p}<0.05)$ in male Sprague Dawley rats with benign prostatic hyperplasia (BPH) compared to healthy rats (Table 1). Daily urinary output was highest in the healthy rats and decreased by $33.19 \%$ in rats with $\mathrm{BPH}$. However, rats with $\mathrm{BPH}$ demonstrated normal daily urinary output following the treatment with Cosmos caudatus ethanolic extract (CCEE), significantly increased by $40.58 \%$ compared to rats with $\mathrm{BPH}$ treated with distilled water (DW). Prostate volume and prostatic index also increased $(\mathrm{p}<0.05)$ in rats with $\mathrm{BPH}$ compared to healthy rats by $37.78 \%$ and $15.79 \%$, respectively. Following CCEE consumption, prostate volume and prostatic index of rats with BPH decreased $(\mathrm{p}<0.05)$ by $32.26 \%$ and $18.18 \%$, respectively, compared to rats with BPH treated with DW.

Reduction in daily urinary output and increment in prostate volume and prostatic index suggested that testosterone successfully induced BPH in male rats as previously reported (Yang et al., 2014). Testosterone has been demonstrated to be involved in BPH by triggering abnormal proliferation of epithelial and stromal cells in prostate gland, resulting in inflammation and enlargement of prostate. As the prostate enlarges, it can compress the urethra and reduce daily urinary output (Barkin, 2011) as exhibited by the current study (Table 1). 
Table 1: Effect of Cosmos caudatus ethanolic extract (CCEE) on daily urinary output, prostate volume and prostatic index of rats with benign prostatic hyperplasia (BPH). Values are presented as mean \pm standard error of mean $(\mathrm{n}=8)$.

\begin{tabular}{lccc}
\hline & Healthy+ DW & BPH + DW & BPH + CCEE \\
\hline Urine $(\mathrm{ml})$ & $4.61 \pm 0.27^{\mathrm{a}}$ & $3.08 \pm 0.39^{\mathrm{b}}$ & $4.33 \pm 0.25^{\mathrm{a}}$ \\
Prostate volume (ml) & $0.45 \pm 0.03^{\mathrm{a}}$ & $0.62 \pm 0.04^{\mathrm{b}}$ & $0.42 \pm 0.02^{\mathrm{a}}$ \\
Prostatic index (\%) & $0.19 \pm 0.02^{\mathrm{a}}$ & $0.22 \pm 0.0 \mathrm{E}^{\mathrm{b}}$ & $0.18 \pm 0.0 \mathrm{E}^{\mathrm{a}}$ \\
\hline
\end{tabular}

Value with different superscript letters within the same row shows significant difference at $\mathrm{p}<0.05$. Note: $\mathrm{DW}=$ distilled water, $\mathrm{BPH}=$ benign prostatic hyperplasia, CCEE $=$ Cosmos caudatus ethanolic extract

Previous study indicated that antioxidant able to inhibit prostate enlargement and inhibit the activation of inflammatory agents such as interleukins and cyclooxygenase (Agati et al., 2012). In the present study, C. caudatus was found significantly $(\mathrm{p}<0.05)$ reduced the size of prostate in rats with BPH. Medicinal and nutritional studies have proven that $C$. caudatus is rich with antioxidant properties (Bunawan et al., 2014). We suggest that, $C$. caudatus could be a $\alpha$-blockers and $5 \alpha$-reductase inhibitors. However, this is yet to be determined.

The current study also showed that sperm parameters (sperm count, sperm motility and the percentage of normal sperm) were not statistically ( $\mathrm{p}>0.05)$ affected by BPH and CCEE (Table 2). All parameters demonstrated decrement pattern following BPH induction compared to healthy rats but not statistically significant. Consumption of CCEE by rats with BPH showed some changes (increment in sperm count and the percentage of motile sperm but decrement in the percentage of normal sperm) but again not statistically significant $(\mathrm{p}>0.05)$.

Table 2: Effect of Cosmos caudatus ethanolic extract (CCEE) on sperm parameters of rats with benign prostatic hyperplasia (BPH). Values are presented as mean \pm standard error of mean $(n=8)$.

\begin{tabular}{lccc}
\hline & Healthy +DW & BPH + DW & BPH +CCEE \\
\hline Sperm count $\left(10^{6} / \mathrm{ml}\right)$ & $53.3 \pm 2.6$ & $51.8 \pm 3.4$ & $54.9 \pm 2.9$ \\
Motile sperm $(\%)$ & $55.2 \pm 3.7$ & $52.9 \pm 3.1$ & $53.7 \pm 1.3$ \\
Normal sperm $(\%)$ & $83.9 \pm 1.9$ & $77.2 \pm 1.7$ & $73.8 \pm 2.3$ \\
\hline
\end{tabular}

All data values within the same row shows no significant difference (p>0.05) Note: $\mathrm{DW}=$ distilled water, $\mathrm{BPH}=$ benign prostatic hyperplasia, $\mathrm{CCEE}=$ Cosmos caudatus ethanolic extract

Only a few reports have addressed the effect of BPH on spermatogenesis and sperm quality, especially in animal models. According to Fontbone (2011), BPH in dogs and as well as in human is likely to be one of the major causes of impaired fertility. Lowseth and co-workers (1990) documented that degenerative changes and incomplete spermatogenesis in the seminiferous tubules was more prominent in older dog with $\mathrm{BPH}$ compared to younger dog. This partly explain why no significant changes in sperm parameters were observed in the current study since we utilised relatively young rats. In human beings, the number of Leydig cells, Sertoli cells and other interstitial cells in the testes decline in man with $\mathrm{BPH}$, coincidence with the aging processes (Johnson et al., 1984). In addition, our finding on the effect of $C$. caudatus on sperm parameters in agreement with the previous report. Booh et al., (2015) reported that $C$. caudatus showed no significant effect on sperm parameters of mice.

\section{CONCLUSION}

In conclusion, oral treatment of Cosmos caudatus ethanolic extract for 20 days showed inhibition of testosteroneinduced BPH in rats without compromising sperm parameters. However, further pharmacological and phytochemical studies are currently in progress to determine their mode of action.

\section{ACKNOWLEDGEMENT}

All authors are greatly indebted to the Faculty of Applied Sciences and the Institute of Research Management and Innovation (IRMI), Universiti Teknologi MARA for providing all research facilities and administrative support to accomplish this research.

Financial support and sponsorship: This work was financially supported by the Ministry of Higher Education, Malaysia through the Fundamental Research Grant Scheme (600-RMI/FRGS 5/3 64/2013) and IRMI, Universiti Teknologi MARA through the Lestari Grant (600-IRMI/DANA 5/3/LESTARI 0088/2016).

Conflict of Interests: There are no conflicts of interest.

Author's Contribution: All authors were involved in the writing, revision and final approval of the paper.

\section{REFERENCES}

Afriyie DK, Asare GA, Bugyei K, Adjei S, Lin JM, Peng J, Hong ZF. Treatment of benign prostatic hyperplasia with Croton membranaceus in an experimental animal model. J Ethnopharmacol, 2014;157:90-98.

Agati G, Azzarello E, Pollastri S, Tattini M. Flavonoids as antioxidants in plants: Location and functional significance. Plant Sci, 2012;196:67-76.

Asare GA, Afriyie D, Ngala RA, Appiah AA, Anang Y, Musah I, Adjei S, Bamfo-Quaicoe K, Sule D, Gyan BA, Arhin P, Edoh DA. Shrinkage of prostate and improved quality of life: Management of BPH patients with Croton membranaceus ethanolic root extract. Evid Based Complement Alternat Med, 2015; doi.org/10.1155/2015/365205.

Barkin J. Benign prostatic hyperplasia and lower urinary tract symptoms: Evidence and approaches for best case management. Can J Urol, 2011;18:14-19.

Booh MJ, Hashim N, Ismail NH, Daud D, Samsulrizal N, Yahya MFZR. Effects of Cosmos caudatus on sperm quality of mice, Mus musculus. Malays Appl Biol, 2015;44:89-93.

Bunawan H, Baharum SN, Bunawan SN, Amin SN, Noor NM. Cosmos caudatus Kunth: A traditional medicinal herb. Global J Pharmacol, 2014;8:420-426.

Casarett GW. A one solution stain for spermatozoa. Stain Technol, 1953;28:125-127.

Farah Amna O, Nooraain H, Noriham A, Azizah AH, Nurul Husna R. Acute and oral subacute toxicity study of ethanolic extract of Cosmos caudatus leaf in Sprague Dawley rats. Int $\mathrm{J}$ of Biosci Biochem Bioinforma, 2013;3:301-305.

Fernandez CDB, Bellentani FF, Fernandes GSA, Perobelli JE, Favareto APA, Nascimento AF, Cicogna AC, Kempinas WDG. Dietinduced obesity in rats leads to a decrease in sperm motility. Reprod Biol Endocrinol, 2011;9:32-41.

Fontbone A. Infertility in male dogs: Recent advances. Rev Bras Reprod Anim, 2011;35:266-273. 
Johnson L, Zane RS, Petty CS, Neaves WB. Quantification of the human Sertoli cell population: Its distribution, relation to germ cell numbers and age-related decline. Biol Reprod, 1984;31:785-795.

Lowseth LA, Gerlach RF, Gillett NA, Muggenburg BA. Agerelated changes in the prostate and testes of the Beagle dog. Vet Pathol,1990;27:347-353.

McVary KT. A review of combination therapy in patients with benign prostatic hyperplasia. Clin Ther, 2007;29:387-398.

Mustafa RA, Abdul Hamid A, Mohamed S, Bakar FA. Total phenolic compounds, flavonoids and radical scavenging activity of 21 selected tropical plants. J Food Sci, 2010;75:C28-C35.

Sarbishegi M, Khani M, Salimi S, Valizadeh M, Aval FS. Antiproliferative and antioxidant effects of Withania coagulans extract on benign prostatic hyperplasia in rats. Nephro-Urol Mon,2016; doi.org/10.5812/numonthly.33180.

Schmidt M, Polednik C, Roller J, Hagen R. Cytotoxicity of herbal extracts used for treatment of prostatic disease on head and neck carcinoma cell lines and non-malignant primary mucosal cells. Oncol Rep,2013;29:628-636.
Yang X, Yuan L, Xiong C, Yin C, Ruan J. Abacopteris penangiana exerts testosterone-induced benign prostatic hyperplasia protective effect through regulating inflammatory responses, reducing oxidative stress and anti-proliferative. J Ethnopharmacol,2014;157:105113.

\section{How to cite this article:}

Daud D, Fekery NFM, Hashim N. Reproductive Health of Rats with Benign Prostatic Hyperplasia Following Cosmos caudatus Ethanolic Extract Consumption. J App Pharm Sci, 2017; 7 (06): 202-205. 